\title{
La Comunicación en la gestión de la Responsabilidad Social Empresarial
}

\author{
Recibido: 02 de noviembre de 2010 \\ Aceptado: 30 de junio de 2011 \\ Publicado: 31 de octubre de 2011
}

\author{
Sandra Orjuela Córdoba \\ sandraorjuelacordoba@gmail.com \\ Universidad Monteávila (Venezuela)
}

Resumen: El mundo empresarial actual está ávido de modelos gerenciales que le permitan no sólo ser más eficiente, sino enmarcarse a un desarrollo e interés por la construcción de una conciencia social, buscando una sociedad más justa y solidaria.

La crisis económica de los últimos años ha obligado a la empresa revisar y tomar conciencia de la importancia de mantener comportamientos éticos para fortalecer la gestión de su propia identidad desde los valores y, a partir de allí, gestionar su imagen y reputación corporativa de forma transparente y confiable.

En este contexto, la comunicación y el relacionamiento responsable con los públicos de interés se convierten en los ejes y motores de la Responsabilidad Social Empresarial (RSE), buscándose un triple beneficio: empresa-sociedad-Estado.

Palabras claves: Comunicación, Responsabilidad Social Empresarial, públicos de interés, relacionamiento, identidad, imagen, reputación.

Abstract: The business world is eager for management models that allow being more efficient, surrounded by a development and interest in building a social consciousness.

The financial crisis of recent years has led the company to review and be aware of the importance to maintain ethical behavior, to strengthen the management of their own identity from values and from there to manage your image and corporate reputation transparent and reliable. 
In this context, communication and responsible relationship with its stakeholders, become a driving force of Corporate Social Responsibility within the organization, feeding each other, looking for a triple win: Business-Society-State.

Key words: Communication, Corporate Social Responsibility, Stakeholders, Relationship, Identity, Image, Reputation.

\section{Introducción}

La empresa actual está enfrentando grandes cambios a nivel estructural, social, comunicacional y de relaciones. Desde hace algunos años el mundo empresarial ha empezado a preguntarse: ¿cuál es la relación más sana que debe tener con la sociedad en la cual está inmersa?, ¿la filantropía es suficiente para responder a la realidad actual?, ¿cómo se puede llegar a ser más responsable y asumir compromisos frente a la realidad caótica que se está viviendo?

Los límites de la organización se expanden y con ellos su comunicación y relacionamiento con más públicos y, por ende, su responsabilidad hacia estos. De allí que ahora los temas relacionados a la "empresa socialmente responsable", "ciudadanía corporativa", "gobierno corporativo", "sostenibilidad", "medio ambiente", "derechos humanos aplicados en la organización", estén ocupando mayor espacio de estudio y análisis.

La organización comunica de forma implícita (exposición de sus acciones y prácticas) y explícita (discurso y/o reflexión consciente sobre la RSE). Comunica al hacer y al no hacer; al hablar y al no hablar; por ello es vital que se tome conciencia de la importancia que tiene una alineación estratégica de la comunicación y las relaciones como parte de la misma Responsabilidad Social Empresarial ya que se alimentan entre sí. No hay RSE sin comunicación y la comunicación en el siglo que corre debe estar marcada por la responsabilidad, ya que la empresa se comunica con su entorno y este, a su vez, responde a la empresa a través de la comunicación, construyendo cultura desde su propia identidad y proyectándola a través de sus comportamientos, comunicación y relacionamiento con sus audiencias claves.

En la actualidad, diversas especialidades (Relaciones Públicas, Publicidad, Mercadeo, comunicación interna y externa; comunicación de marcas, comunicación para el cambio, comunicación para la gestión de las crisis) invaden todos los ámbitos de vida en el que nos desenvolvemos. En ese sentido, la RSE no se puede desligar de la comunicación, ya que es la clave para lograr una sinergia entre la organización y sus diferentes stakeholders (públicos de interés), con los cuales trabaja, convive y transforma.

La empresa contemporánea no es la misma de hace 10 ó 20 años: factores como la globalización, la conciencia por un mundo sustentable, la importancia por la preservación del medio ambiente, el interés por el desarrollo de un capital humano integral en las empresas y la preocupación por una sociedad más justa y equitativa, está llevando a que las organizaciones se den cuenta que ya no pueden seguir trabajando sólo por un rendimiento 
económico, ya que su operación afecta directamente al medio ambiente, al entorno que lo rodea y a todas las personas con las que se contacta.

Por lo tanto, el no trabajar por ser una empresa socialmente responsable, no sólo afectaría su licencia para operar, sino que le traería consecuencias a nivel de su imagen y reputación, ya que toda institución pública o privada valora enormemente el nivel de favorabilidad que puede tener entre sus públicos. Al respecto Fernández Pedemonte (Paladino y Álvarez, 2006: 8-9) sostiene lo siguiente:

Aun cuando buscara en primer lugar la maximización de la rentabilidad, una miopía social de la empresa jugaría en contra de la reputación pública que necesita para alcanzar la rentabilidad buscada [...] Los medios deben preocuparse por mejorar su gestión y las empresas, su comunicación. Esto es exacto siempre que no se olvide la peculiaridad que tienen los productos y los recursos humanos de los medios y no se descuide tampoco el supuesto de que antes que como transmisoras de mensajes, las empresas tienen una responsabilidad social como generadoras de riqueza (responsabilidad con el desarrollo del país, con la creación de empleo, con la contribución tributaria, con el apoyo de políticas públicas) [...] Para vender, la empresa no puede dejar de hablar acerca de sus productos y servicios, acerca de sí misma (de su marca, de su identidad) y de sus valores. Los valores de la empresa se insertan en los valores sociales, difundidos desde los medios de comunicación. La empresa no puede articular sus valores de manera inteligible para la sociedad si carece de sensibilidad hacia los valores emergentes en ella. Antes de hablar, la empresa debe escuchar".

Los límites de la empresa cada vez se amplían y está más a la vista de sus públicos o steakholders, que la organización comunica a través de lo que hace y hasta de lo que deja de hacer; comunica con sus mensajes planificados, a través de sus marcas, productos y servicios; con su comportamiento legal, fiscal y financiero; con su relación con los proveedores; con la comunidad, a través de los empleados y sus familias; y en general, con todos los públicos con los que deba relacionarse de acuerdo con la naturaleza y entorno del negocio.

Es de vital importancia entender que no basta con tener un departamento encargado de planificar y emitir mensajes unificados referidos a la identidad corporativa, sino que debe tener conciencia de su alta responsabilidad como constructor social, ya que como expresa Drucker, la empresa también influye sobre la cultura de las personas y de la sociedad a través de la comunicación.

\section{La investigación}

Dado el complejo mundo en el que la empresa debe transitar en la actualidad, consideramos vital proponer como objetivos principales de estudio entender el enfoque y elementos que conforman la visión de la RSE, para luego analizar el papel de la comunicación en la vivencia y proyección de esa Responsabilidad Social.

Este trabajo se basa en un análisis de contenido, a partir de la lectura detallada de especialistas nacionales e internacionales en RSE, así como de la comunicación estratégica 
en las organizaciones, para determinar tendencias, diferencias y puntos de coincidencia a partir de la abstracción, para luego comparar con experiencias propias, trabajadas desde la asesoría directa en esos temas. Esta modalidad permitió ampliar la visión de la situación desde lo teórico a lo práctico.

Como hipótesis de trabajo, se planteó la relación directa y simbiótica de la comunicación y la RSE, como fuerzas que se alimentan una a la otra y que dependen entre sí para su supervivencia en la empresa pública y privada del siglo XXI.

\section{Entendiendo la Responsabilidad Social Empresarial}

\subsection{Antecedentes}

Desde hace más de 100 años, las empresas en mayor o menor medida, han realizado esfuerzos filantrópicos ${ }^{1}$ por lograr un equilibrio y justicia con la sociedad en la que se desarrollan y conviven, pero fue en la década del setenta del siglo pasado, cuando Milton Friedman, puso en el tapete el término RSE y, desde ese momento, se convirtió en un tema de interés para académicos, empresarios, investigadores e intelectuales del mundo.

Guédez (2011) recuerda que en ese momento Friedman la definió como "aquella a través de la cual se genera el máximo rendimiento al accionista, siempre y cuando ello se haga en el marco de la ley y sin afectar a los otros". Para complementar estos antecedentes Méndez (2011), asevera lo siguiente:

En el siglo pasado no se hablaba de Responsabilidad Social Empresarial (RSE) sino de la "responsabilidad de empresas en asuntos sociales", es decir, la intervención de los proyectos de la empresa en beneficio del país. Pero, en términos fundamentales, las empresas tenían dos opciones: cumplir lo indicado por las leyes con sus trabajadores, que se conocía como "bien social integral"; y otra de las tendencias que se desarrolló fuertemente fue cumplir con la comunidad, a través de la filantropía, en otros momentos llamada "inversión social empresarial", o "desarrollo social de intervención privada" [...] En el siglo pasado, la RSE se refería a lo que podían hacer las empresas por sus trabajadores o por su entorno o la sociedad [...] Ya a finales del siglo se empiezan a dar movimientos internacionales importantes, producto del impacto de la globalización, cuando se percibe que las grandes economías del mundo son empresariales, y de alguna manera se empieza a revisar que no solo los Estados eran responsables del efecto de la pobreza, del cambio climático, sino que las corporaciones también debían tener algún tipo de responsabilidad [...] Se empiezan a desarrollar fuertes discusiones en foros internacionales como la ONU o consejos empresariales, para buscar un concepto de RSE más profundo".

1.- Filantropía se puede entender como los aportes monetarios que una empresa realiza a una comunidad o individuo, pero no logra mejorar la calidad de vida, ni proyectos a largo plazo para beneficio de los involucrados. Algunos como Michael Hopkins, en Olcese et álii (2008:284), consideran que "la filantropía no lleva al desarrollo sostenible, y por lo tanto, debería ser abandonada". Consideramos que no se debe llegar a tal extremo, ya que con los tiempos que corren, esta práctica tiene su función específica: dada la existencia de tantas carencias sociales es mejor que la empresa asuma su responsabilidad con la sociedad, así sea desde esta posición y no que se comporte indiferente, sin hacer nada por aportar a su entorno. 
En la década del ochenta, varios teóricos consideraron poco pertinente e injusto hablar de la responsabilidad solo con los accionistas, ampliando el rango de influencia de la organización hacia otros públicos (empleados y clientes).

Edward Freeman, en los años noventa, introduce una novedad que cambiará para siempre la forma de gestionar tanto la comunicación, las RR. PP. y la RSE: la teoría de los stakeholders o "grupos de interés". Recuerda Guédez que en este enfoque "la RSE no es para atender ni al accionista, ni al trabajador ni al cliente, sino que es para atender a todas aquellas personas y aquellos grupos que, cuando deciden y actúan, me impactan a mí como empresa, o cuando yo, como empresa, actúo o decido los impacto a ellos. Es un concepto muchísimo más amplio".

En el nuevo milenio surgen nuevos elementos que enriquecen a la RSE: la moral y la ética; la problemática ambiental y la sostenibilidad aparecen en el debate conceptual y entran a formar parte concomitante de la definición de la RSE, para ampliarla y complementarla, dándole mayor trascendencia dentro de los modelos de gestión empresarial.

\subsection{Definiendo la RSE}

Consideramos de vital importancia homologar las definiciones sobre las cuales estaremos trabajando, con el fin de evitar equivocaciones en los lectores, ya que actualmente y a pesar del auge de este tema, aún hay mucha confusión en cuanto al concepto de la RSE y a las variables que la alimentan.

Iniciamos por considerar la Responsabilidad Social Empresarial como la forma de entender la gestión empresarial en que las empresas comienzan a tener más en cuenta el impacto social y ambiental de su negocio, tratando de generar rentabilidad para los empresarios y bienestar social. Para ello, tratan de tener en cuenta la necesidad y expectativas de los grupos sociales a los que impactan (directa e indirectamente) con la actividad de la organización o empresa. Cuando se habla de grupos sociales, podemos homologarlo al de públicos de interés: accionistas, empleados y sus familias, proveedores, autoridades, comunidad, consumidores, medio ambiente, medios de comunicación y las demás audiencias que la empresa considere pertinente.

No hay una definición única de la Responsabilidad Social Empresarial, por ello consideramos apropiado mencionar algunas de las conceptualizaciones más conocidas y trabajadas, con el fin que el lector tenga elementos para sacar sus propias conclusiones:

- El Consejo Empresarial Mundial para el Desarrollo Sostenible la considera como un compromiso continuo de actuar éticamente y de contribuir al crecimiento económico, al mismo tiempo que mejora la calidad de vida de la fuerza laboral y de sus familias, como de la comunidad local y de la sociedad en general.

- Para el Programa Nacional de Competitividad, Consejo de Fundaciones Privadas de Guatemala y Banco Mundial (1999) es la “operación de una empresa que cumple o excede las expectativas éticas, legales, comerciales y públicas que la sociedad tiene de ella, en función de todos sus públicos: accionistas, empleados, clientes, proveedores, gobierno, industria y comunidad". 
- El Instituto ETHOS de Empresas y Responsabilidad Social (Brasil) entiende la RSE como una forma de gestión que se define por la relación ética de la empresa con todos sus públicos con los cuales se relaciona y por el establecimiento de metas empresariales compatibles con el desarrollo sustentable de la sociedad; preservando recursos ambientales y culturales para las generaciones futuras, respetando la diversidad y promoviendo la reducción de las desigualdades sociales.

- El Libro Verde de la Unión Europea, concibe la RSE como "la integración voluntaria, por parte de las organizaciones, de las preocupaciones sociales y medioambientales en sus operaciones y en sus relaciones con sus interlocutores" (Guédez, 2008: 99).

- El BID, entiende que "son las prácticas de la empresa que tratan de evitar el daño, al mismo tiempo que promueven el bienestar de los grupos de interés al acatar regulaciones y normas vigentes, yendo voluntariamente más allá de lo requerido”.

Estas conceptualizaciones nos permiten ver que los márgenes de este tema se ensanchan cada día más y seguirán haciéndolo debido a la dinámica del mundo empresarial y social que exigen respuestas de parte de los Estados, las empresas y las sociedades, a los múltiples problemas que el mundo vive.

A manera de común denominador, entre las diferentes concepciones, podemos ver que las acciones de Responsabilidad Social van más allá de cumplir estrictamente la ley: se basan en la ética y se nutren de compromisos que trascienden el negocio mismo, aunque sin "demonizar" que la generación de riqueza es un fin natural para toda empresa productiva. Además, implica la continuidad de los esfuerzos sociales e implica a todos los stakeholders con los que se comunica y relaciona a nivel interno y externo.

Para complementar el entendimiento de la RSE, nos apoyamos en Méndez (2004:167), quien presenta una síntesis de las diversas características y concepciones sobre las variables que la conforman:

Figura 1: Concepciones sobre RSE.

CONCEPCIÓN

Producir como responsabilidad fundamental
- En función del principio de la responsabilidad.

- Impacto social de la actividad productiva.

- Generación de empleo y contribución fiscal.

- Enfoque interno.

- Beneficia a accionistas, consumidores y Estado.

- El público no lo identifica como acción social, le exige más. 
Trabajo social industrial

Filantropía empresarial y corporativa
- Dimensión interna de la empresa.

- En función del principio justicia social.

- Modalidad ejecución directa.

- Enfoque interno.

- Se mantiene vigente.

- Se ha desarrollado hacia otros públicos.

- Se identifica con salario social y paternalista.

- Dimensión externa a la empresa

- Principios de solidaridad y contribución.

- Modalidad de apoyo a terceros.

- Con instrumentos financieros y no financieros.

- Pasó de los dueños a las empresas.

- Se critica por asistencialista.

- Dimensión de desarrollo social.

- Principios de cooperación y reciprocidad.

- Enfoque en la comunidad y el entorno.

- Modalidad de ejecución directa y cogestión.

- Implica retorno de la inversión.

- La más utilizada actualmente.

- Se critica por búsqueda de imagen, reputación o lealtad.

Gestión de impacto socioambiental
- Dimensión de desarrollo sustentable.

- Principios de respeto y compensación.

- Modalidad de ejecución directa y alianzas.

- Se percibe como licencia social para operar.

- Utilizada por petroleras y extractivas.

- Se critica por querer paliar los costos sociales y ambientales de la producción.
- Dimensión política de participación empresarial.

- Principios de corresponsabilidad y participación.

- Modalidad fundamentalmente con alianzas.

- Participación en los asuntos públicos.

- Actualmente es un término innovador.

- La empresa se ve como actor fundamental en la vida del país.

- Genera sospecha por participación en políticas públicas. 
El debate no ha concluido. Por el contrario, se sigue enriqueciendo de la dinámica entre el sector académico y el sector empresarial; el enfoque desde lo público, lo privado y el "tercer sector", que se alimenta de la propia realidad crítica que vive el mundo. El contexto actual está exigiendo una redefinición de cómo se ha entendido hasta el presente la relación empresa- sociedad-individuo, logrando que la dinámica comunicacional y relacional también sea revisada para adaptarse a esta nueva situación global y organizacional.

\section{La organización responsable como actor comunicativo}

La empresa se ha entendido, por muchos años, como un ente que debe generar riqueza, que da trabajo a la gente, que ofrece productos y servicios. Sin embargo, con el tiempo y los cambios culturales, políticos y sociales, la empresa se ha dado cuenta que su objeto ya no es tan "simple" y su función va más allá: no es sólo generar riqueza, ya que tiene una relación bidireccional imposible de romper con su entorno. Por ese motivo, la comunicación de la empresa es fundamental: la manera de comunicarse (medios, formatos, públicos) va a determinar su cultura, su imagen y reputación corporativa. Aunque se gestionen (o no) se debe recordar que todo lo que la empresa hace y comunica genera un vínculo con su entorno.

Es importante entender que esa empresa (a través de sus comportamientos, de su comunicación y reracionamiento) no sólo está proyectando su cultura, sino creando una cultura a su alrededor: el conocimiento y difusión de su misión, visión, objetivos y valores empresariales forman parte de la vida de personas y agentes que tienen alguna relación con la organización (proveedores, accionistas, ONG, comunidad, entre otros).

La empresa debe entender que todo lo que hace (y cómo lo hace) construye significados para el entorno, lo cual es muy importante a tener en cuenta, pues esto se puede aprovechar para la generación de valores en la sociedad, a través de la comunicación de su propia identidad, bebiendo de la retroalimentación que le puedan generar sus stakeholders.

Algunas personas han sostenido que la RSE es una moda o que responde a los movimientos "anti-empresa". La verdad es que los expertos consideran que es parte de su esencia y, por tanto, irrenunciable del "deber ser" de la empresa. Para Paladino, esta condición de irrenunciabilidad de la RES no significa, desde luego, que las empresas no pueden renunciar a ella: significa que no pueden hacerlo sin altos costos, tanto para su propia definición y su propio desarrollo como instituciones relevantes dentro del escenario público, así como de las diferentes comunidades (locales, nacionales, internacionales) en las que las empresas llevan a cabo sus acciones.

La vida de la empresa y su estructura de negocio (basada en la ganancia) ha cambiado, pues la misma inercia a la que ha llevado la globalización exige interés y presenta otras concepciones empresariales. Espera mayor compromiso con el medio ambiente, solidaridad y mejora de su entorno lo que lleva a comprender lo siguiente: 
- Ser parte de ese entorno genera responsabilidades a la empresa.

- El entorno merece ser desarrollado por el bien que ese desarrollo significa en sí mismo, aunque ese bien termine beneficiando a la empresa.

- No resulta empresarialmente razonable ni posible esperar que ese entorno o contexto se desarrolle por sí solo, sin la promoción y el apoyo de la empresa, aspectos ambos (la promoción y el apoyo) íntimamente vinculados con la cultura, el sentido y la comunicación.

Es importante no caer en apasionamientos y entender que la empresa posee una misión con un elemento de productividad, de generación de riqueza a través de la oferta de productos y servicios, sin olvidar que, a su vez, debe generar empleo y un ambiente laboral enriquecedor para sus empleados. Así se forma una cultura corporativa basada en valores, los cuales impactarán en el desarrollo de su capital humano y este en la mejora de la productividad, sin olvidar el componente humano y la responsabilidad que la empresa tiene en: a) los planes de carrera para el desarrollo profesional y personal de su equipo humano; b) la producción de productos y servicios no sólo rentables, sino que agreguen valor a la sociedad, ya sea a través de su consumo o por los esquema post-venta; y c) la proyección que tiene todo su quehacer en la relación que mantiene con sus públicos externos.

En suma, la RSE debe ser una labor de desarrollo y responsabilidad social tanto hacia su interior como hacia su exterior, en la formación de significados culturales, que marquen a todos los vinculados con ella.

La empresa ya no se entiende sólo como un ente que comunica y sus públicos reciben y actúan en consecuencia. Las organizaciones actuales tienen una gran responsabilidad como generadoras de cultura a través de sus mensajes y de sus acciones. Dada esta situación, es muy importante entender la comunicación mucho más allá como una herramienta, una táctica; no sólo como un proceso o un elemento más dentro del engranaje de la empresa.

Si bien algunos la consideran un "conjunto de políticas" o acciones de comunicación institucional asociadas a la labor del negocio, para estar a la par de los adelantos y desarrollo a nivel gerencial y empresarial, es importante entender la comunicación desde un punto de vista estratégico: es hora de que el comunicador pase de ser un "obrero" a ser un "estratega", un gestor de la comunicación interna y externa; un profesional que apoya y está inserto en el plano directivo, que no se limite a "bajar" los mensajes de las directivas hacia los demás planos de la empresa.

Es el momento que en las organizaciones se entienda la labor comunicacional como un proceso transversal y, sobre todo, como un factor que agrega valor a la gestión empresarial, apoyando a la alta directiva a entender la gestión comunicacional no sólo para maximizar los beneficios económicos, sino para la gestión de valores.

De esta forma, el desarrollo de la ética y la responsabilidad social no debe ser visto como actividades puntuales de la empresa hacia la comunidad, sino como valor vivencial dentro del equipo de trabajo, marcando su labor profesional de cada día, cimentando cada actividad y cada relación en valores en significados más cercanos y más profundos con sus receptores. 
Las decisiones acerca del nivel y tipo de comunicación en la empresa la deciden sus directivas. Sin embargo, es importante que el rol y la importancia que le den a ella se vea reflejado en la influencia y proyección que la organización tendrá en la cultura del entorno en que se desenvuelve.

\section{La comunicación de la RSE}

Vilanova, Lozano y Dinares (2006) nos recuerdan que las empresas siempre han tenido que presentar informes y rendición de cuentas (accountability), entendiéndose como "el final de un proceso en el cual se juzga o evalúa el resultado de acciones previamente realizadas".

En la actualidad, el accountability ha tomado importancia en la gestión de la RSE: sólo ha cambiado el contexto, pues el enfoque tradicional (shareholder) tomaba como único público a los accionistas, caracterizándose por ser un proceso en el cual las empresas deben responder por sus acciones y consecuencias; requiere de unas responsabilidades y funciones definidas en cuanto a la jerarquía y el poder. Además, el proceso se instrumenta mediante el ejercicio de control y reporting por parte de aquellos que tienen poder sobre la empresa (accionistas).

En el enfoque actual, centrado en los stakeholders (públicos de interés), el proceso está basado en la responsabilidad que amplía sus ámbitos y stakeholders, entendiéndose que cada individuo que se sienta o pueda verse afectado por las acciones de la empresa, puede demandar la responsabilidad de esta. En este nuevo enfoque, el accountability se concibe como un proceso dinámico, en el cual los stakeholders pueden participar en todos los niveles de toma de decisiones de la empresa y pueden exigirle responsabilidad.

Frente a esta realidad, uno de los retos que se presenta es el de la rendición de cuentas a diferentes públicos, con diversos intereses y perfiles, los cuales en ocasiones son casi desconocidos para la organización. Los autores recalcan la problemática existente con este enfoque de accountability, ya que requiere de una estructura de poder clara en la empresa, para poder definir, medir y ejercer el proceso de accountability.

Figura 2: Alcances y dimensiones del accountability.

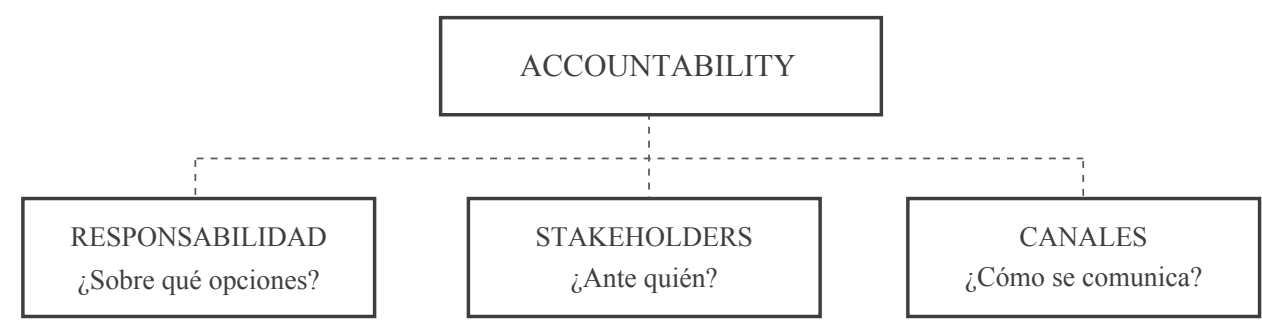

Fuente: Vilanova, Lozano y Dinares (2006). 
Es importante aclarar que el accountability no es sinónimo de una memoria social o una alianza con organizaciones del tercer sector: es un proceso que sobrepasa el mero hecho de informar lo que se ha realizado hasta el momento. Este enfoque exige de la organización un desarrollo sostenible de sus propuestas, basado en su práctica empresarial, por lo que involucra a todas las áreas funcionales y productivas de la empresa.

El entendimiento de la comunicación como un proceso que atraviesa a toda la organización (y en el que todos los miembros son responsables de esta) es la visión de comunicación corporativa que consideramos se convierte en la otra cara de la moneda de la RSE. Además, comparten metodologías de acercamiento y conocimiento con sus públicos a través de diagnósticos de necesidades y diseñan modelos y mapas de comunicación a partir de su relación con los diferentes públicos internos, intermedios y externos (stakeholders). Las dos áreas se definen a sí mismas desde la gestión misma de la organización, agregando valor a su funcionamiento y productividad.

La organización informa todo el tiempo y a veces olvida que debe escuchar primero y luego adaptar sus respuestas (mensajes) y medios (canales) al perfil comunicacional y relacional de los diversos públicos, de acuerdo con la identidad corporativa que se quiera transmitir, para luego proyectar y posicionar una imagen y reputación acordes con los objetivos de negocio, corporativos y de comunicación.

Retomando lo anterior: para realizar una planificación estratégica de comunicación para la RSE, se debe iniciar por determinar los públicos de interés para la organización, de acuerdo con su cultura corporativa, objetivos organizacionales, comunicacionales y de RSE, para luego definir estrategias, tácticas, diseñar el tipo de mensajes y canales, así como la intencionalidad de estos, para lograr el impacto deseado, tanto desde la comunicación, como de la RSE. Por supuesto, no olvidar la definición de indicadores de gestión, con el fin de dar mayor rigor y seriedad a las propuestas dentro de la organización.

\subsection{Los stakeholders}

Según Escudero (2010: 25-26) este término aparece por primera vez en 1963, incluido en un memorándum del Stanford Research Institute, para referirse a "aquellos grupos sin cuyo apoyo la organización dejaría de existir". La lista de stakeholders originalmente incluía a dueños, empleados, clientes, proveedores y financistas. Desde entonces el concepto fue desarrollado con énfasis por la literatura de cuatro disciplinas de investigación: Planificación Corporativa, Teoría de Sistemas, RSE y Teoría Organizacional (Reed, 1983; Freeman, 1984; Freeman y McVea, 2001). Freeman (Escudero, 2010: 27) propone dos definiciones de stakeholder:

-Acepción amplia. Cualquier grupo o individuo identificable que pueda afectar el logro de los objetivos de una organización o que es afectado por el logro de los objetivos de una organización (grupos de interés público, grupos de protesta, agencias gubernamentales, asociaciones de comercio, competidores, sindicatos, así como segmentos de clientes, accionistas y otros).

-Acepción restringida. Cualquier individuo o grupo identificable respecto del cual la organización es dependiente para su supervivencia (empleados, segmentos de clientes, ciertos proveedores, agencias gubernamentales claves, accionistas, ciertas instituciones financieras y otros). 
Para efectos de la planificación estratégica de la comunicación, se recomienda utilizar el enfoque amplio de stakeholder con el fin de lograr un entendimiento más global y profundo de la dinámica comunicacional a nivel interno y externo, así como de la organización con su entorno. Cada empresa y gerente debe conocer cuáles son los stakeholders con los que se comunica; su perfil y necesidades de contenidos; relacionamiento e identificación de su dinámica social.

Este enfoque es el más adecuado para lograr una gestión unificada y planificada de la comunicación de RSE por las siguientes razones:

- Proporciona un marco de trabajo estratégico simple y flexible, para adaptarse a los cambios que se generen sobre la marcha.

- Genera una visión amplia y equilibrada para integrar las relaciones y los objetivos del negocio y, por ende, comunicacionales.

- Se entiende a la organización desde su dinámica social con sus stakeholders y no sólo desde su dimensión productiva.

- Exige que la organización observe y analice con detenimiento la realidad que se genera, más allá de sus propios muros, identificando semejanzas para compartir, diferencias para tender puentes y estrechar lazos, con el fin de construir un diálogo constructivo, generar valor a la organización y a la sociedad en la cual está inmersa.

- Proporciona un conocimiento de personas reales, individuales, no sólo de fenómenos sociales, que en ocasiones generan una sombra sobre lo que realmente debe ser importante para la institución y se queda en planes, acciones o estadísticas, que al final no producen beneficios reales.

- Ofrece a las directivas un enfoque integrado para la toma de decisiones, que le permitirá satisfacer a cada stakeholder según su perfil y necesidades específicas, buscando relaciones profundas y a largo plazo, que a posteriori serán el soporte de su reputación organizacional, en beneficio de todo el negocio.

Cuando se habla de la afectación de la organización desde sus stakeholders y cómo esta misma puede afectarlos, se denota una vía de doble sentido que implica intercambio, diálogo y la construcción de una cultura social, donde la RSE se convierte en un valor organizacional que se proyecta a su entorno para generar bienestar y progreso entre sus públicos.

Para efectos de la comunicación de la RSE, se propone un sencillo modelo desde el enfoque de multistakeholders, que puede servir de mapa de ruta para la conceptualización y planificación de la comunicación, adaptándolo a la necesidad puntual de cada institución pública o privada. 
Figura 3: Radio de acción de los multistakeholders.

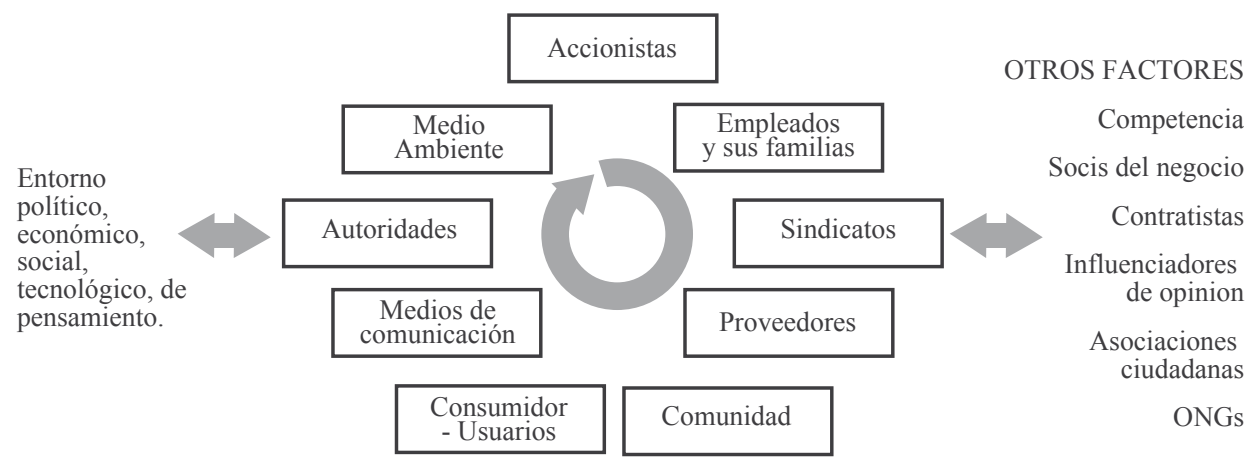

Fuente: Elaboración propia.

\subsection{La comunicación interna y externa: el motor de la organización}

Se puede entender la empresa como "aquella estructura multiorganizada dirigida por personas en la que, con el concurso de otras personas, reclutadas y formadas al efecto, se trabaja en pos de un objetivo común y donde, y con la puesta en marcha de procesos, técnicas, herramientas e instrumentos, se consiguen logros con el objetivo final de la obtención de un beneficio económico que repercute tanto en la propia organización, como en sus integrantes, y consecuentemente, en el conjunto de la sociedad" (Carneiro, 2007: 14).

Cuando se menciona "comunicación corporativa", se piensa en una organización donde los empleados deben estar alineados con la misión, visión, valores, objetivos y filosofía organizacional, olvidándose que se está hablando de personas con emociones, problemas, ilusiones y frustraciones que inciden (en mayor o menor medida) en su desempeño profesional, familiar y en sus relaciones humanas en general, al extremo que afectan la construcción de la identidad de la empresa e inciden en su proyección como agente social en sus propias comunidades.

En la labor diaria de quienes conforman el capital humano, sin importar su lugar en el organigrama (presidente, gerente, director, secretaria u obrero), queda la huella de cómo ven al mundo, de cómo lo entienden en su relación con sus compañeros y, por supuesto, en la manera cómo hacen su trabajo.

La empresa debe trabajar por la formación de un empleado ético, solidario, responsable, que se involucre con lo que pasa en la sociedad y en el medio ambiente; que entienda que la oficina no es una "caja de cristal" donde se puede refugiar de su rol protagónico en la sociedad, para huir de las dificultades, aislándose del entorno. La empresa debe servir para que desarrolle y proyecte el liderazgo que lo convierta en un auténtico agente de cambio social. 
Para lograr ese cambio y generación de líderes sociales, la comunicación se debe gestionar desde los valores institucionales, para luego proyectarlos hacia la sociedad, convirtiendo a cada uno de sus colaboradores en los primeros voceros de lo que es y representa la organización. Para ello es importante que la comunicación sea entendida como el eje transversal que coadyuva en la alineación de la estrategia y de la cultura organizacional, convirtiéndose (dentro de la empresa moderna) en el motor para motivar, informar, generar sentido de pertenencia y lograr cambios en la cultura desde la RSE, promoviendo la inclusión de la ética, la divulgación de los modelos y apropiación de prácticas para llegar a ser socialmente responsables.

En las últimas décadas, la empresa ha tenido que enfrentarse a los cambios en los modelos gerenciales, que le han exigido comprender su entorno para aprender de él y adaptarse al mismo.

La organización ha entrado en el proceso de entender que no vende sólo productos y servicios, sino que también transmite confianza y credibilidad. Este esfuerzo comunicacional es la proyección de la identidad corporativa (gerenciada desde la comunicación interna) que permite el contacto con sus públicos externos. Suele ser complementada con la planificación de comunicaciones mercadológicas (mercadeo, publicidad, promoción, entre otras) y así lograr un posicionamiento en el imaginario de sus clientes, usuariosconsumidores, comunidad, proveedores, gobierno, influenciadores de opinión, ONG's, competencia, medio ambiente y otros públicos específicos con los que la empresa (por su origen y naturaleza) tenga relación (embajadas, entidades multilaterales, entre otros).

Drucker nos recuerda que los grandes cambios que se han dado en las empresas: a finales del siglo XIX las estructuras eran totalmente jerárquicas y "militares": en ellas cada miembro hacía casi lo mismo y el número de personas que manejaban conocimientos era mínimo. A partir de la segunda mitad del siglo XX, las empresas iniciaron una evolución rápida y continua basadas en la información y se organizaron (como él bien lo explica) como "equipos de fútbol", donde cada uno es responsable de algo y toma decisiones a partir de ello. Así, cada empleado se veía a sí mismo como un ejecutivo.

Los modelos más modernos de gestión y de comunicación tienden a emplear la red, donde se multiplican los emisores-receptores y se intercambian roles en cuestión de segundos. Además, se construyen equipos de acuerdo con perfiles específicos, acordes al proyecto y objetivo que tenga la organización, con lo cual la forma como se ha entendido hasta hoy la comunicación sigue presentando nuevos retos para lograr una verdadera comunicación exitosa, eficaz y eficiente que agregue valor a la organización y, desde ella, a la sociedad.

\subsubsection{Variables de comunicación}

La comunicación de la RSE debe ser responsable en sí misma. Para ello debe ser confiable, precisa, coherente, oportuna y veraz ${ }^{2}$.

2.- Estas variables provienen del Manual Institucional de Comunicaciones, de HMO Consultores, las cuales sirven de baremo para los proyectos que se dirigen y direccionan desde la misma consultora, entre sus clientes y aliados. 
La confianza implica la esperanza firme que se tiene de algo o alguien, sin más seguridad que la buena fe y la opinión que de él se tiene. Precisión, entendida como la exactitud y concisión en el lenguaje. La coherencia en la comunicación conlleva la actitud lógica y coherente entre lo que se dice y se hace.

La variable de la oportunidad es importante, ya que es conveniente que los públicos reciban los mensajes a tiempo. Por último, pero no menos importante, la veracidad refuerza la confianza de los mensajes que se emiten a los diversos stakeholders, profesando siempre la verdad.

La combinación de estas variables mínimas deben caracterizar a todos los mensajes que sean emitidos por la organización (a nivel implícito y explícito) para lograr una verdadera concepción de comunicación responsable.

Estas constantes deben definir toda la comunicación de tipo organizacional, institucional y mercadológica, a fin de lograr la alineación de los mensajes y comportamientos desde la responsabilidad social de la institución.

\subsubsection{Identidad, imagen y reputación: una tríada exitosa}

\subsubsection{Identidad}

De acuerdo con Marín (2008:79), el modelo de organización actual basado en la RSE, debe orientar sus objetivos al cumplimiento de "resultados económicos positivos, acometer proyectos sociales que repercutan favorablemente en la sociedad en la que se desarrollan sus actividades y contribuir a la protección del medio ambiente".

En este marco, la organización actual asume y vive sus valores, establece normas que marcan su comportamiento y orientan su negocio en búsqueda de la licencia de operación, a través de su adaptación a las exigencias sociales. Esto la lleva a establecer una identidad corporativa propia y perfectamente diferenciada de las otras organizaciones, que le permita responder, de forma veraz y coherente, a los stakeholders con los que se relaciona.

Villafañe (2004: 17) afirma que la identidad corporativa es el "ser" de la empresa. Agrega que solo se le puede entender desde una concepción dinámica, ya que posee atributos permanentes y otros que son cambiantes. Se basa en la gestión de tres ejes: a) historia de la organización, proyecto empresarial que la organización ha emprendido para alcanzar sus metas y su cultura corporativa, expresada por sus "comportamientos expresos" (todo lo observable y que denota la forma de hacer las cosas); b) los valores compartidos, pautas que orientan la acción y las costumbres; y c) las presunciones básicas, que se entienden como las convicciones profundas sobre la realidad, el entorno y hasta su sentido humano, reflejado en sus comportamientos.

\subsubsection{La imagen corporativa}

Para Villafañe (2004: 30-32), la imagen corporativa es "la integración en la mente de sus públicos de todos los inputs emitidos por una empresa en su relación ordinaria con ellos". La imagen se forma en la mente de sus públicos, lo que le da el mayor control a estos, más que a la empresa misma. 
El comportamiento corporativo comprende las actuaciones de la empresa en el plano funcional y operativo de sus procesos productivos. Es el resultado de sus políticas funcionales (financiera, de producción, comercial). La personalidad corporativa es, según Villafañe, el conjunto de manifestaciones voluntarias que la empresa emite con el fin de proyectar una imagen intencional entre sus públicos. En suma, con lo propuesto por el mencionado autor, la imagen es el resultado de la síntesis entre el comportamiento corporativo, la cultura corporativa y la personalidad corporativa.

Para Van Riel, citando a Dowling (1997: 77), la imagen es el "conjunto de significados por los que llegamos a conocer un objeto, y a través del cual las personas lo describen, recuerdan y relacionan. Es el resultado de la interacción de creencias, ideas, sentimientos e impresiones que sobre un objeto tiene una persona".

La imagen corporativa es un tema que ha sido tratado por muchos autores, debido a la importancia que ha tenido desde sus inicios, sobre todo en el área del mercadeo. Es considerado un incentivo para las ventas, atrayendo el mejor capital humano como empleados de la empresa, creando un valor emocional por sobre sus competidores y atrayendo al mayor número de aliados para lograr el éxito empresarial.

Cuando mencionamos la "imagen intencional", la RSE adquiere un puesto preponderante como atributo de imagen, ya que una de las manifestaciones de esa responsabilidad es la voluntariedad, lo que influye positivamente en la percepción de los stakeholders (Marín: 84).

No basta con comunicar los beneficios y valores funcionales, como la calidad de los productos y servicios, los altos estándares de servicio al cliente o su comportamiento en los negocios: se debe añadir la comunicación de los valores sociales (ética y RSE). La comunicación de esos valores funcionales y sociales genera valores emocionales que son la reacción a las señales que envía aquella, con el objetivo de presentar una imagen positiva lo más próxima posible a su identidad corporativa.

Resulta importante señalar que la RSE no sólo debe ser vista como un input para la generación de imagen positiva y reputación favorable, sino como un elemento sinérgico que agrega valor a toda la organización en su relación con sus multistakeholders y el entorno en general, logrando bienestar mutuo a todos sus asociados.

\subsubsection{Reputación y RSE}

Una frase socrática reza así: “el modo de obtener una buena reputación es procurar ser lo que se desea parecer". La reputación es la consecuencia de nuestro comportamiento, de la representación de lo que "se es", lo que "se quiere aparentar" y lo que "se debe ser". Para Guédez (2008: 259) la reputación es la consecuencia simultánea de:

- Ser lo que se es ("transparencia").

- Ser lo que se quiere aparentar (“proactividad").

- Ser lo que se debe ser (“excelencia”). 
La reputación exige transparencia porque es imposible alcanzarla disimulando lo que se es o simulando lo que no se es.

Por un lado, la proactividad se entiende como el actuar afirmativo frente a un estímulo y decidir anticipadamente según lo que se quiere compartir. Por otro, la excelencia se presenta como el esfuerzo continuo y creciente, que no se agota en ninguno de sus logros parciales.

Costa (2009: 76) sostiene que la reputación es parte de la imagen y la considera como una moneda de dos caras: una la relaciona con la "notoriedad" (dimensión cuantitativa, entendida como la recordación) y la "notabilidad" (entendida como el prestigio y la valoración, siendo de carácter más cualitativo). Las dos dimensiones son interdependientes.

Olcese (2008: 178) nos presenta de forma esquemática las diferencias entre "imagen" y "reputación" corporativa:

Figura 4: Diferencias entre imagen y reputación corporativas.

\section{REPUTACIÓN CORPORATIVA}

- Se basa en resultados.

- Es verificable empíricamente.

- Genera valor, consecuencia de la respuesta.

- Carácter estructural y efectos duraderos.

- Resultado del comportamiento corporativo.

- Se genera en el interior de la empresa.

\section{IMAGEN CORPORATIVA}

- Se basa en percepciones.

- Es difícil de objetivar.

- Genera expectativas asociadas con la oferta.

- Carácter coyuntural y efectos efímeros.

- En parte es resultado de la comunicación.

- Se construye fuera de la empresa.

Fuente: Elaboración propia.

Como hemos verificado a lo largo del trabajo, las empresas contemporáneas están expuestas a múltiples presiones, que en ocasiones abren brechas y desigualdad de oportunidades, generando esquemas confusos para la gestión de la identidad, imagen y reputación de las organizaciones. Esto se debe enfrentar a la actitud de múltiples grupos de interés, cuya conciencia de su implicación en el contexto empresarial está creciendo, generando un mayor cúmulo de exigencias éticas, lo que lleva a que las organizaciones que quieran sobrevivir respondan con comportamientos socialmente responsables.

La organización del siglo XX no enfrenta los mismos desafíos en el siglo XXI y debe entender que está siendo observada como nunca antes, llevando a redimensionar su propia 
naturaleza. Al respecto, presentamos una síntesis de características que Guédez (2008: 289) ofrece para entender los cambios que enfrenta la organización. Asimismo, describe cómo la comunicación y la RSE toman una nueva dimensión dentro de la planificación de la empresa exitosa de este nuevo siglo:

Figura 5: Nuevos desafíos empresariales.

\begin{tabular}{lll}
\hline CARACTERÍSTICAS & SIGLO XX & SIGLO XXI \\
\hline Posicionamiento & Calidad y precio & Innovación, servicio y ética \\
Interacción & Negociante (ganar-perder) & Negociador (ganar-ganar) \\
Relaciones & Competencia & Cooperación \\
Imagen & A partir de promoción & A partir de reputación \\
Vinculación social & Ayuda ocasional & Responsabilidad Social \\
Capital & Financiero e intelectual & Social y ético \\
Fundamento & Negocio & Ética \\
Impulso & Información y conocimiento & Sabiduría \\
Normas & Prohibitivas & Transparencia y preactivas \\
Medición & Valor económico agregado (VEA) & Valor ético agregado (VEA)
\end{tabular}

Fuente: Elaboración propia a partir de Guédez (2008).

\section{Conclusiones}

En la actualidad se habla de "gobierno corporativo", "Responsabilidad Social Empresarial", "gerencia ética", "respeto al medio ambiente", "gerencia de valores", "ciudadanos corporativos", entre otros conceptos que describen la labor de la comunicación orientada a alinear objetivos, valores, estrategias y mensajes, para darlo a conocer y así lograr su entendimiento interno y externo.

La RSE se está convirtiendo en un atributo de imagen (a proyectar y posicionar) y en un comportamiento verificable que alimenta y dinamiza la reputación corporativa. Así, podemos asegurar que la comunicación corporativa y la RSE se nutren entre sí. A partir de la sinergia que logran en su interrelación, generan y comparten significados que son percibidos por los diversos stakeholders, fortaleciendo la gestión estratégica de la comunicación.

Las personas, como seres sociales, no pueden abstraerse de su entorno. Para lograr el éxito y satisfacer sus necesidades, se deben comunicar entre sí para establecer relaciones que les permitan la convivencia. Por eso es importante que los líderes organizacionales se apalanquen en el gestor de comunicación y lo vean como un agente que agrega valor a su gestión. La labor de este gestor no sólo debe ser táctica, sino estratégica, que contribuya al desarrollo de una empresa más justa y humana. 
Cada vez más se encuentran casos donde los líderes de comunicación están dirigiendo también los esfuerzos de RSE, por lo cual su compromiso es aún mayor, obligándolos a entender y asumir parte de la responsabilidad que tiene la organización en la construcción de nuevos significados culturales en la sociedad. Esto se logra gracias a la comunicación bidireccional y en red, así como la creación de modelos puntuales que se adapten a la realidad propia de cada organización y a su relación y dinámica con sus stakeholders.

El camino es arduo y retador, tanto que Solari (2007:71) cuestiona el hecho de que se está dejando de lado a la comunicación como "actor principal" de este nuevo paradigma y se pregunta cuál es la esencia de la misma, a lo cual responde:

La comunicación es expresión social. Ponerla a favor de unos pocos, pero en contra de la gente, es ponerla en contra de sí misma. Es desaprovecharla. Pero, peor aún, es maltratarla, faltarle al respeto; desperdiciar su potencia. Significa impedirle alcanzar su cometido natural.

Las crisis en el entorno y la dinámica organizacional, así como los cambios que se presentan en los niveles de articulación y relacionamiento de la empresa con sus stakeholders, conllevan a que los procesos deban garantizar el cumplimiento de las políticas de responsabilidad social definidas desde la conciencia de la organización y es allí donde, según Yepes et álii (2007: 213) "los flujos de información, tanto vertical como horizontalmente, representan un reto a superar por parte de los responsables de gestionar la RSE al interior de la empresa. Y ello ya sea porque la información se demora en llegar a quien toma la decisión o porque las decisiones tomadas para corregir desviaciones o situaciones de riesgo se demoran en bajar a todos los niveles".

Así como se pueden presentar inconvenientes en la comunicación interna, también se puede homologar esta situación a nivel externo, acrecentando la problemática y repercutiendo en la consecución de los objetivos reputacionales, sociales, económicos y ambientales, propuestos por la organización, lo que lleva a definir a la comunicación como una variable determinante en el éxito o fracaso de la gestión de la RSE.

\section{Fuentes consultadas}

Carneiro, M. (2007). Guía de Responsabilidad Social Interna y Recursos Humanos. Andalucía: Consejo Andaluz de Relaciones Laborales (CARL).

Costa, J. (2009). Imagen Corporativa en el siglo XXI. Buenos Aires: La Crujía.

Drucker, P. (1997). Drucker, su visión sobre la administración, la organización basada en la información, la economía, la sociedad. Norma.

Escudero, G. (2010). Bien Común y stakeholders. La propuesta de Edward Freeman. Pamplona: Universidad de Navarra.

Guédez, V.

_(2011). Entrevista concedida al periódico venezolano El Universal (17/VII/ 2011). 
_(2008). Ser Confiable. Responsabilidad social y reputación empresarial. Caracas: Planeta.

_(2006). Ética y práctica de la responsabilidad social empresarial. El aporte de la empresa al capital social. Caracas: Planeta.

León, M. (2011). "La RSE es una alternativa que permite a la propia empresa redefinirse”. Extraída el 30/VIII/2011 desde http:/www.eluniversal.com/2011/07/19/la-rse-es-una-alternativa-que-permitea-la-propia-empresa-redefinirse.shtml

Marín, F. (2008). Responsabilidad Social Corporativa y Comunicación. Madrid: Fragua.

Méndez, Ch. (2004). Responsabilidad Social de Empresarios y Empresas en Venezuela durante el siglo XX: Caracas: Strategos Consultores.

Olcese, A; Rodríguez, M. y Alfaro, J. (2008). Manual de la Empresa Responsable y Sostenible. Madrid: McGraw-Hill.

Paladino, M. y Álvarez, C. (2006). Comunicación Empresarial Responsable. Temas y acciones para lograr la responsabilidad social empresaria. Buenos Aires: Granica.

Tovar, E. (2011). "Hay discusiones sobre RSE que no se están dando en el país”. Extraída el 28/ VIII/2011 desde http://www.eluniversal.com/2011/07/19/hay-discusiones-sobre-rse-que-no-seestan-dando-en-el-pais.shtml

Vilanova, M.; Lozano, J. y Dinares, M. (2006). Accountability. Comunicación y Reporting en el ámbito de la RSE. Madrid: Forética.

Villafañe, J. (2004). La gestión profesional de la imagen corporativa. Madrid: Pirámide.

Yepes, G.; Peña, W. y Sánchez, L. (2007). Responsabilidad social empresarial. Fundamentos y aplicación en las organizaciones de hoy. Bogotá: Universidad Externado de Colombia. 